\title{
DIGITAL SOCIAL FUTURES RESEARCH
}

\author{
Sarah Pink*
}

\begin{abstract}
Social research is almost inevitably digital: in its subject matter because the digital, social and material dimensions of our worlds and lives are now inseparably entangled; and in its methods as our research techniques and encounters are, even if indirectly, implicated with digital technologies, platforms and practices. Social scientific renderings of digital technologies and media and everyday life propose a range of discipline-specific ways of understanding this relationship between the online/offline and digital/material, and a large and growing literature about digital methods and practice for research and its dissemination. The new challenge is to advance from this strong base of critical research and scholarship within the social sciences and humanities, in two ways. First towards interdisciplinary interventions that will bring theory, methods and concepts into dialogue with technology and design disciplines, and policy and industry agendas; and second to engage with emerging digital technologies and communication, including Artificial Intelligence (AI), Machine Learning, and Automated Decision Making (ADM), and the new socialities, everyday life practices and business models associated with these technological possibilities.
\end{abstract}


Social research is almost inevitably digital: in its subject matter because the digital, social and material dimensions of our worlds and lives are now inseparably entangled; and in its methods as our research techniques and encounters are, even if indirectly, implicated with digital technologies, platforms and practices. Social scientific renderings of digital technologies and media and everyday life propose a range of discipline-specific ways of understanding this relationship between the online/offline and digital/material, and a large and growing literature about digital methods and practice for research and its dissemination. The new challenge is to advance from this strong base of critical research and scholarship within the social sciences and humanities, in two ways. First towards interdisciplinary interventions that will bring theory, methods and concepts into dialogue with technology and design disciplines, and policy and industry agendas; and second to engage with emerging digital technologies and communication, including Artificial Intelligence (AI), Machine Learning, and Automated Decision Making (ADM), and the new socialities, everyday life practices and business models associated with these technological possibilities.

Emerging technologies are often portrayed as primed or ready to launch into markets, but not (yet) established as ubiquitous. They are represented in dominant science, technology, business, policy narratives as having potential to change, impact on or influence society. For example, Scientific American describes their 2018 top 10 emerging technologies as 'Disruptive solutions that are poised to change the world', and asks 'How will technology change your life in the near future?'. Digital anthropologists (and social science and humanities scholars) have created a strong base of research that shows that technologies themselves change neither the world nor individual people's lives. Rather we understand technologies as coming into being in the world and our lives in relation to what people do with them. A significant literature demonstrates how digital technologies, platforms, software and practices associated with them - including for examples those relating to smartphones, computer games and more - have become part of, appropriated into and improvised with in everyday life. However, the study of emerging technologies differs from that of the finished product, which might subsequently be consumed, or appropriated by its user, since it involves the study of technologies that might be inevitably unfinished. For example, the Tesla car which can be changed through a software update, and therefore is experienced not as a complete product, but through the owner's anticipation of its status as a changing product (Lindgren et al. 2018).

Thus as new technologies - which might change during our ownership or use of them, interact 'intelligently' with us, learn from or with us in the course of our relationships with them, and take decisions - start to inhabit the horizons of the world that we both begin to experience and anticipate, we need new theoretical and methodological modes of understanding the ways these

\footnotetext{
${ }^{1}$ See https://www.scientificamerican.com/article/the-top-10-emerging-technologies-of-2018/.
} 
technologies configure with people and other non-human things and species in everyday life and society. For example, automated decision-making, artificial intelligence and predictive data analytics are increasingly possible and present in our everyday lives, and configure with societal, political and economic structures, and the inequalities in which these are already entangled. Digital social research has multiple roles in this new context. Here I focus on a particular strand of research, through the example of the study of digital technologies and media in everyday life. In this field I have proposed going beyond a focus on how digital technologies are experienced, appropriated and used by consumers, towards a theoretical, methodological and empirical focus encapsulated by a Digital Futures Anthropology (Pink forthcoming) and an Interventional Design Anthropology of Emerging Technologies. In common these two moves draw on design anthropological theory and practice developed in my collaborative work, to emphasize the emergent and inevitably incompleteness of digital-material configurations (Pink et al. 2016), notions of possibility and uncertainty (Akama et al. 2018), futures as non-predictive (Pink and Salazar 2017) and the need for new methodologies and ethics in a future oriented research agenda for researching the possible but as yet unknown (Pink and Salazar 2017; Pink 2017). A critical and interventional design anthropology of emerging technologies moreover seeks to: engage with policy, industry and technology design organizations; create responsible and ethical interventions in everyday life and technology design environments; and contest the dominant narratives that advance the 'solutionist' (Morozov 2013) paradigm, which is coherent with problematic claims that human behavior can be changed and wellbeing improved through the influence of technology.

I call for digital social research that is critical, involves interdisciplinary and inter-sector engagements, which engages with and contests how technological futures are conceptualized in other disciplines and outside academia. Digital social researchers would engage practically and conceptually in the processes through which technology is designed and is emerges in society and everyday life, are understood and implemented. To achieve this, I propose: bringing together social science research and theory to contest the concepts that are used in prevalent discourses and technology design processes; collaboration with those whose ideas and practices are different to ours, to demonstrate the new insights social research brings to complex problems; and new modes of engagement outside academia, through video, visualizations of human experience, card sets and more. This is a work in progress and I invite readers to join this endeavour, and learn how, with colleagues and collaborators internationally, we are developing design anthropological research, scholarship and intervention ${ }^{2}$.

\footnotetext{
${ }^{2}$ View my Why the World Needs Anthropologists keynote (2018) here: https://www.youtube.com/watch?v=xrRPu3kE-G0.
} 


\section{REFERENCES}

Akama, Y., Pink, S and Sumartojo, S. (2018) Uncertainty and Possibility: new approaches to future making. London: Bloomsbury, https://doi.org/10.5040/9781350002722.

Lindgren, T., Fors, V., Pink, S., Bergquist, M., and Berg, M. (2018) 'On the Way to Anticipated Car UX', NordiCHI '18 Proceedings of the 10th Nordic Conference on Human-Computer Interaction, October 1-3, 2018, Oslo, Norway, pp. 494-504, https://doi.org/10.1145/3240167.3240219.

Morozov, E. (2013) To Save Everything, Click Here: Technology, Solutionism, and the Urge to Fix Problems that Don't Exist. London: Penguin Books.

Pink, S. (2017) 'Ethics in an uncertain world: between theory and practice' in Pink, S., Fors, V., and O'Dell, T. (eds) Working in the between: theoretical scholarship and applied practice. Oxford: Berghahn

Pink, S. (forthcoming) 'Digital Futures Anthropology' in Geismer, H., and Knox, H. (eds). Digital Anthropology. London: Bloomsbury.

Pink, S., Ardevol, E., and Lanzeni, D. (eds) (2016) Digital Materialities: Design and Anthropology. Oxford: Bloomsbury. 